\title{
An Evaluation of Major Determinants of Health Care Facilities for Women in India
}

\author{
Dr. Manisha A.Mehrotra ${ }^{1}$, Ms. Saumya Chand ${ }^{2}$ \\ ${ }^{I}$ (Assistant Professor, Department of Economics/ Banaras Hindu University/India) \\ ${ }^{2}$ (Research Scholar, Department of Economics/ Banaras Hindu University/India)
}

\begin{abstract}
The women in India belong to various socio-economic backgrounds and are sometimes marginalized or neglected on the gender discrimination when it comes to basic healthcare The fact that the typical female advantage in life expectancy is not seen in India suggests that there are systematic problems with women's health. Indian women have high mortality rates, particularly during childhood and in their productive years.

Most women who did not receive health care during pregnancy said they thought it was unnecessary. Another reason for the low levels of prenatal care is lack of adequate health care centers. It was estimated that 16 percent of the population in rural areas lives more than 10 kilometers away from any medical facility.

Keeping these issues in mind this paper focuses on various determinants of health care facilities such as: Residence, Media Exposure, Females \& Partner's Education and Females \& their Partner's Employment, Religion of Household Head and Female's Economic Status.

Using Household data from Demographic Health Survey and by using ordered Logistic Regression Analysis, this paper seeks to examine the above mentioned socio economic factors which are responsible for poor health status of women in India on the basis of parameters like Delivery at Health Facility, Antenatal care, Level of anemia, Family planning, Knowledge of STD and Prenatal care.
\end{abstract}

Key words: Female child mortality, Gender discrimination, Health facility, Pre natal care, Socio-economic backgrounds.

\section{Introduction}

India is one of the few countries in the world where women and men have nearly the same life expectancy at birth. The fact that the typical female advantage in life expectancy is not seen in India suggests that there are systematic problems with women's health. Indian women have high mortality rates, particularly during childhood and in their productive years. The health of Indian women is intrinsically linked to their status in society. The women in India belong to various socio-economic backgrounds and are sometimes marginalized or neglected when it comes to basic healthcare. Women however, are the very backbone of any society and if one needs a healthy society, the women need to be well taken care off. Research on women's status has found that the contributions Indian women make to families often are overlooked and instead they are viewed as economic burden.

\subsection{Review of Literature}

Miller (1989),Murthi, Anne and Dreze (1995), Gupta and Bhat (1997), George (1998), Bhat and Zavier (2003), Mishra., Roy and Rutherford (2004), Dyson and Moore (1983), Krishnaji (1987), Siddhanta, Nandy and Agnihotri (2003), Pandey (2003), Hill and Upchurch (1995) and Acharaya \& Kumar (2004) explained the extent of gender differences in infant and child mortality in terms of gender differences in health status ,disease incidence, preventive and curative treatment and social status.

"In many parts of the world, women receive less attention and health care than man do and particularly girls often receive very less support than boys. As a result of this gender bias, the mortality rates of females often exceed those of males in these countries". [1] This is an important issue because gender discrimination that contributes to poorer health status for girls than for boys is likely to be the main pathway for excess female child mortality. Such discrimination occurs in (a girl) receives less attention than would be bestowed upon a son. She is less warmly clad, she is probably not so well fed as a boy would be and when ill, her parents are not likely to make the same strenuous efforts to ensure her recovery". [2]

Sugathan, Mishra and Retherford (2001), Kishor and Parasuraman (1998), Stephenson and Tusi (2002), Bourne \& Walker (1991), McNay, Arokiasamy and Cassen (2003), Dyson and Moore (1983) and Rustagi (2004) evaluated the status of women in India with different indicators such as of women's work, education, health, survival, safety and participation in public/private decision-making.

Sudha, Rajan,( 1999) George (2002), Rutherford and Roy (2003), Bose (2007), Visaria (2007) examined the causes for eliminating the girl child. It indicates that they are rooted in rituals and perceptions that go back centuries: the fear of having to pay for a girl's dowry, the belief that for true salvation a son should 
perform the last rites, the conviction that lineage and inheritance run through the male line and that a son will look after his parents in their old age, whereas the daughters will belong to another family. Tied up to all this is the old perception of seeing only men as the bread earners.

\subsection{Nature of the problem}

Poor health has repercussions not only for women but also their families. Women in poor health are more likely to give birth to low weight infants. They also are less likely to be able to provide food and adequate care for their children. Finally, a woman's health affects the household economic well-being, as a woman in poor health will be less productive in the labor force.

\subsection{Purpose \& Objective of the Study}

While women in India face many serious health concerns, this research paper focuses on various determinants of health care facilities such as: Residence, Media Exposure, Female's Education, Partner's Education, Female's Employment, Partner's Employment, Religion of Household Head and Female's Economic Status.

The main objective of this paper is to examine the above mentioned socio economic factors which are responsible for poor health status of women in India on the basis of different parameters like Delivery at Health Facility, Antenatal care (ANC), Level of anemia, Family planning, Knowledge of Sexually Transmitted Diseases ( STD) and Prenatal care(PNC).

\section{Data and Methods}

The analysis is based on National Family Health Survey -3(NFHS), Individual data for women. The statistical method used in this study is the ordered logistic regression.

The following predictor variables are included in the analysis:

Table 1

\begin{tabular}{|l|l|}
\hline Dependent Variables & Independent Variables \\
\hline Delivery at Health Facility & Residence \\
Antenatal care & Media \\
Level of anemia & Female's Education \\
Family planning & Partner's Education \\
Knowledge of STD & Female's Employment \\
Prenatal care & Partner's Employment \\
& Religion of Household Head \\
& Female's Economic Status \\
\hline
\end{tabular}

\section{Status of Women's Health}

In India most of the women are still not receiving health facilities. Poor condition of women can be seen in availing nutritious food, prevalence of anemia and nutritional status of women.

Women's autonomy has been determined by three areas- control over finance, decision making power and freedom of movement. Women with greater freedom of movement obtained higher level of antenatal care and were more likely to use safe delivery care.

The influence of women's autonomy on the use of health care appears to be as important as other determinant such as education. [3]

According to NFHS 3 almost one out of every five women in India did not receive any antenatal care for their last birth in the five years preceding the survey. There is wide variation in the use of antenatal care services among the states. Utilization of antenatal care is almost universal in Kerala, Tamil Nadu and Goa. In addition, more than 90 percent of women received ANC in Andhra Pradesh, Maharashtra, West Bengal, Karnataka, Delhi and Punjab. The percentage of women receiving antenatal care was lowest in Bihar. In India there is broad North- South contrast between areas of low female autonomy and unfavorable demographic performance on the one hand and comparatively high female autonomy and relative favorable demographic performance on the other. The particularly high birth and death rates that continue to prevail throughout most of Northern India must be seen within the context of local kingship arrangements. [4]

\subsection{Nutritional Status of Women in India}

For women, weight and height measurement can be used to access health risks. A widely used indicator of nutritional status is the body mass index (BMI), which is defined as the weight in kilograms divide by height in meters squared $(\mathrm{kg} / \mathrm{m} 2)$. This indicator is used to assess both thinness and obesity. It is helpful in detecting the risk of health or nutritional disorders. A BMI of less than 18.5 indicates chronic energy deficiency (CED). 
At the other end of the spectrum, women with a BMI of 25.0-29.9 are considered to be overweight and those with a BMI of 30.0 or above are identified as obese.

According to NFHS-3 there are $36 \%$ women in India have chronic energy deficiency and 13\% women are overweight. Level of CED is high in the states of Chhattisgarh, Orissa, Madhya Pradesh, Bihar, Jharkhand and Uttar Pradesh. CED is particularly pronounced for rural women, illiterate women, and women living in households with a low standard of living and among those women who don't consume proper nutritious food.

3.2 Bias in the Intra-Household Distribution of Food and Nutritive Elements

In India, sex preference is mainly manifested in the form of excessive mortality of female child. The poor health status of female relatively to males is found to be due to the discrimination against females in the allocation of food and health care within household. There is gender discrimination in childhood feeding, immunization coverage, treatment seeking and nutritional status. [5] According to NFHS-3, women consume less nutritious food than man.

Table 2

Percentage distribution of women and men age 15-49 consuming specific foods at least once a week in India,2005-06

\begin{tabular}{|l|l|l|}
\hline Type of food & Men & Women \\
\hline Milk or curd & 67.2 & 55.4 \\
\hline Pulses or beans & 90.7 & 89.5 \\
\hline Dark green leafy vegetables & 93.6 & 92.9 \\
\hline Fruits & 47.4 & 39.8 \\
\hline Eggs & 41. & 32.3 \\
\hline Fish & 31.3 & 28.2 \\
\hline Chicken or meat & 28.3 & 22.7 \\
\hline Fish or chicken/meat & 40.9 & 35.4 \\
\hline
\end{tabular}

Sources : National Family Health Survey-3 (2005-06), Department, Family Welfare, Government of India

The pattern of food consumption TABLE $2 \& 3$ shows that men are more likely than women to consume milk or curd regularly. Men are less likely than women to completely abstain from eating chicken, meat, fish, or eggs. The last row of each panel shows the frequency of consumption of fish, chicken, or meat. Overall, 33 percent of women and 24 percent of men are vegetarians according to this measure.

Table 3

Food Consumption for Women and Men in India-NFHS-3

\begin{tabular}{|c|c|c|c|c|}
\hline \multirow{2}{*}{ Type of Food } & \multicolumn{3}{|c|}{ Frequency of consumption } \\
\cline { 2 - 5 } & \multicolumn{2}{|c|}{ Daily } & \multicolumn{2}{c|}{ Never } \\
\cline { 2 - 5 } & Women & Men & Women & Men \\
\hline Milk or curd & 39.8 & 46.7 & 11.4 & 7.0 \\
\hline Pulses or beans & 52.7 & 52.1 & 0.9 & 0.9 \\
\hline Dark green, leafy vegetables & 64.2 & 59.1 & 0.3 & 0.4 \\
\hline Fruits & 12.7 & 13.1 & 3.5 & 2.6 \\
\hline Eggs & 3.5 & 5.2 & 34.8 & 23.3 \\
\hline Fish & 6.3 & 6.2 & 37.5 & 30.5 \\
\hline Chicken or meat & 0.9 & 1.2 & 35.1 & 25.6 \\
\hline Fish or chicken/meat & 6.8 & 6.9 & 32.6 & 23.9 \\
\hline
\end{tabular}

\subsection{Maternal Health}

Maternal health is a major indicator of status of women as it depends on socio economic conditions and facilities provided by government. Poor status of maternal health reveals the low status of women in the society. In India a higher percentage of women are not receiving health facilities during pregnancy which has direct and indirect effect on survival condition of women as well as their child. 
Table 4

Maternal Care Indicators for Births during the Five Years

Preceding the Survey - India NFHS-3, 2005-06

\begin{tabular}{|c|c|}
\hline Percentage who received all recommended types of antenatal care1 & 15.0 \\
\hline Percentage of births delivered in a health facility & 38.7 \\
\hline Percentage of deliveries assisted by health personnel & 46.6 \\
\hline Percentage of deliveries with a postnatal check-up & 41.2 \\
\hline $\begin{array}{c}\text { Percentage of deliveries with a postnatal check-up within } \\
\text { two days of birth }\end{array}$ & 37.3 \\
\hline
\end{tabular}

Table 5

Maternal Care Indicators for Births in India-NFHS-3, NFHS-2 and NFHS-1

\begin{tabular}{|c|c|c|c|}
\hline Indicators & NFHS-3 & NFHS-2 & NFHS-1 \\
\hline $\begin{array}{c}\text { Percentage who received antenatal care } \\
\text { vercentage who had at least three antenatal care } \\
\text { visits }\end{array}$ & 76.9 & 65.8 & 64.6 \\
\hline $\begin{array}{c}\text { Percentage who received antenatal care within the } \\
\text { first trimester of pregnancy }\end{array}$ & 50.7 & 44.2 & 43.9 \\
\hline Percentage of births delivered in a health facility & 43.0 & 33.1 & 24.9 \\
\hline Percentage of deliveries assisted by health personnel & 48.8 & 33.6 & 26.1 \\
\hline
\end{tabular}

\subsection{Maternal Mortality}

Deaths due to pregnancy and during the child birth are common among women in the reproductive age groups. [6]

Bulletin on maternal mortality in India shows a decline in maternal mortality rate from 301 in 2001-03 to 254 in 2004-06.

Table 6

Maternal Mortality Rate in India \& Major States 2001-3 \& 2004-06 (Latest)

\begin{tabular}{|c|c|c|c|}
\hline S. No. & India \& Major states & $2001-2003$ & $2004-06$ \\
\hline & India & 301 & 254 \\
\hline 1 & Andhra Pradesh & 195 & 154 \\
\hline 2 & Assam & 490 & 480 \\
\hline 3 & Bihar & 371 & 312 \\
\hline 4 & Gujarat & 172 & 160 \\
\hline 5 & Haryana & 162 & 186 \\
\hline 6 & Karnataka & 228 & 213 \\
\hline 7 & Kerala & 110 & 95 \\
\hline 8 & Madhya Pradesh & 379 & 335 \\
\hline 9 & Maharashtra & 149 & 130 \\
\hline 10 & Orissa & 358 & 303 \\
\hline 11 & Punjab & 178 & 192 \\
\hline 12 & Rajasthan & 445 & 388 \\
\hline 13 & Tamil Nadu & 134 & 111 \\
\hline 14 & Uttar Pradesh & 517 & 440 \\
\hline 15 & West Bengal & 194 & 141 \\
\hline
\end{tabular}

Source: Special bulletin on maternal mortality

3.5 Trends in Maternal Care Indicators

TABLE 4,5 \& 6 shows trends in key maternal care indicators over time. All of the measures improved substantially between National Family Health Survey-1 and National Family Health Survey-3. The first two ANC indicators (percentage with any ANC and at least three ANC visits) improved much more rapidly between NFHS-2 and NFHS-3 than between the first two surveys. The other three indicators improved at a more even pace throughout the period. Over the entire period between NFHS-1 and NFHS-3, most of the indicators improved at a rate of about one percentage point per year. The slowest increase was in the percentage that had at least three antenatal care visits. All of the indicators except the timing of the first ANC visit increased much more rapidly in rural areas than in urban areas. 
Despite these improvements, at least half of women did not receive appropriate care for their most recent birth. Thus, renewed efforts are required to ensure that women are provided with adequate antenatal and delivery care.

\subsection{Anemia among Women and Men in India}

Anemia is a major health problem in India, especially among women and children and it can result in maternal mortality, weakness, and diminished physical and mental capacity, increased morbidity from infectious diseases, prenatal mortality, premature delivery and low birth weight.

NFHS show gender differential in anemia levels for women and men $.55 .3 \%$ of women and $24.2 \%$ percent of men whose hemoglobin level was tested were found to be anemic. Thirty-nine percent of women are mildly anemic, 16 percent are moderately anemic and 2 percent are severely anemic. The prevalence of anemia for ever-married women has increased from 52 percent in NFHS-2 to 56 percent in NFHS-3. Therefore, the anemia situation has worsened over time for both women and young children.

\subsection{Antenatal Care}

Almost one in four women (23 percent) who gave birth in the five years before NFHS-3 received no antenatal care (ANC), ranging from one percent or less in Kerala, Goa and Tamil Nadu to 66 percent in Bihar.[7] In addition to Bihar, at least 40 percent of pregnant women did not get any antenatal care in Jharkhand, Arunachal Pradesh and Nagaland.

NFHS-3 shows the most common hurdle among the eight asked about are the distance to a health facility and the least common is getting permission to go. Notably, almost one-fifth of women report that not having a female provider is a concern and for one-tenth of women, finding someone to go with them is a problem.

\subsection{Family Planning Knowledge and Use}

Knowledge of contraception is nearly universal: 98 percent of women and 99 percent of men age 15-49 know one or more methods of contraception.[8] Over 94 percent of women and men know about female sterilization. Male sterilization, by contrast, is known only by 79 percent of women and 87 percent of men. Ninety-three percent of men know about condoms, compared with 74 percent of women. More than four in five women and men know about contraceptive pills. Knowledge of contraception is widespread even among adolescents: 96 percent of young women and 97 percent of young men have heard of a modern method of contraception. Two-thirds of currently married women have used a family planning method at some time in their lives. Since NFHS-2, ever use of any method among currently married women has increased by 11 percentage points. The increase is greatest for spacing methods; ever use of condoms and the rhythm method has increased by 6 percentage points each.

In general we can say that most women who did not receive health care during pregnancy said they did not because they thought it was unnecessary .[9] Thus, there is a definite need to educate women about the importance of health care for ensuring healthy pregnancies and safe childbirths. Another reason for the low levels of prenatal care is lack of adequate health care centers. It was estimated that 16 percent of the population in rural areas lives more than 10 kilometers away from any medical facility.

Place of birth and type of assistance during birth have an impact on maternal health and mortality. [10] Births that take place in non hygienic conditions or births that are not attended by trained medical personnel are more likely to have negative outcomes for both the mother and the child. Anemia, which can be treated relatively simply and inexpensively with iron tablets, is another factor related to maternal health and mortality.

\section{Empowerment Indicators}

4.1 Employment and cash employment for Women and Men in India Employment and control over income for currently married women and a currently married man is a better way to understand the relative status of married women.

Table 7

Employment and cash employment for Women and Men in India

\begin{tabular}{|c|c|c|}
\hline & Women & Men \\
\hline $\begin{array}{c}\text { Percentage employed in the past 12 months } \\
\begin{array}{c}\text { Among those currently married women employed in the past 12 } \\
\text { months, percentage earning cash }\end{array}\end{array}$ & 42.8 & 98.8 \\
\hline \begin{tabular}{c} 
Amo.2 \\
\hline
\end{tabular}
\end{tabular}

Accordingly, for currently married women and men, the percentage employed at any time during the 12 months preceding the survey are $42.8 \%$ and $98.8 \%$ respectively. Percentage of women is near about half of men's employment as shown in TABLE 7. 
4.2 Women's participation in decision making

TABLE 8 shows the percent distribution of currently married women according to the person in the household who usually makes specific decisions. There is no decision for which a majority of currently married women alone are the main decision makers. Of the four decisions asked about, currently married women, irrespective of urban or rural residence, are most likely to make the decision about purchases for daily household needs mainly by themselves: however, even this decision is made mainly alone by only one-third of all currently married women. Only 27 percent of currently married women make decisions about their own health care mainly by themselves and only 11 percent make decisions about visits to their own family or relatives by themselves. Women are least likely to make decisions mainly by themselves about major household purchases.

Table 8

Women's participation in decision making

\begin{tabular}{|c|c|c|c|c|c|c|}
\hline \multicolumn{7}{|c|}{ Percent distribution of currently married women by person who usually makes decisions about four kinds } \\
\hline of issues, India, 2005-06 & $\begin{array}{c}\text { Mainly } \\
\text { Decision }\end{array}$ & $\begin{array}{c}\text { Mainly } \\
\text { respondent }\end{array}$ & $\begin{array}{c}\text { Respondent and } \\
\text { husband jointly }\end{array}$ & $\begin{array}{c}\text { Some } \\
\text { else }\end{array}$ & Other & Missing \\
\hline Own health care & 27.1 & 35.1 & 30.1 & 6.3 & 1.3 & 0.1 \\
\hline $\begin{array}{c}\text { Major household } \\
\text { purchases }\end{array}$ & 8.5 & 44.4 & 32.2 & 12.0 & 2.8 & 0.1 \\
\hline $\begin{array}{c}\text { Purchases of daily } \\
\text { household needs }\end{array}$ & 32.4 & 27.7 & 24.7 & 12.3 & 2.8 & 0.1 \\
\hline $\begin{array}{c}\text { Visits to her family } \\
\text { or relatives }\end{array}$ & 10.7 & 49.8 & 26.8 & 10.4 & 2.2 & 0.1 \\
\hline
\end{tabular}

This proportion is as low as 9 percent for India as a whole. Joint decision making is most common for decisions about visits to the respondent's family or relatives, followed by decisions about major household purchases. It is least common for decisions about daily household purchases. When husbands are the main decision makers, they most often make decisions about major household purchases, followed closely by decisions about the respondent's own health. For all decisions, the likelihood that a woman will take the decision mainly by herself, as well as the likelihood that she will do so jointly with her husband, are higher in urban areas than in rural areas. In contrast, the husband or someone other than the respondent or her husband is more likely to be the main decision maker in rural areas.

\subsection{Women's access to money and credit}

TABLE 9 shows the percentage of women with access to money, knowledge of credit programmes, and freedom of movement and percentage who have used credit programmes. The proportion of women who have some money of their own that they themselves can decide how to use is from 44.6 percent whereas only 15 women have a bank or savings account that they them- selves use. Knowledge about micro-credit programmes and their use is very limited. Only $36 \%$ of women have the knowledge of a micro credit and only $4 \%$ have taken a loan from micro credit programme.

\section{Table 9}

Women's access to money and credit

\begin{tabular}{|c|c|c|c|}
\hline \multicolumn{2}{|c|}{ Women's access to money } & \multicolumn{2}{c|}{$\begin{array}{c}\text { Women's knowledge and use of micro credit } \\
\text { programmes }\end{array}$} \\
\hline $\begin{array}{c}\text { Percentage who have money } \\
\text { that they can decide how to use }\end{array}$ & 44.6 & $\begin{array}{c}\text { Percentage who know of a micro } \\
\text { credit programme }\end{array}$ & 38.6 \\
\hline $\begin{array}{c}\text { Percentage who have a bank or } \\
\text { savings account that they } \\
\text { them- selves use }\end{array}$ & 15.0 & $\begin{array}{c}\text { Percentage who have taken a loan } \\
\text { from a Micro credit programme }\end{array}$ & 4.0 \\
\hline
\end{tabular}

\subsection{Freedom of Movement}

Freedom of movement outside the home is an important aspect of women's autonomy and empowerment.

NFHS-3 asked women if they were usually allowed to go to three different places - the market, the health facility, and to places outside the village or community - alone, only with someone, or not at all. Only about half of all women are allowed to go to the market or to the health facility alone. Only 38 percent are allowed to travel alone to places outside the village or community. While, thirteen percent of women are not allowed to go to the market at all. 
A fundamental element of empowerment is the rejection of a normatively prescribed power of men over women and of unequal rights and privileges on the basis of the sex of an individual. Data shows that near about $20-40 \%$ women still believe that a husband is justified for hitting or beating his wife.

In NFHS-3, domestic violence is defined to include violence by spouses as well as by other household members. Data shows that $35.4 \%$ women in India experience physical or sexual violence. $26.9 \%$ experienced physical, 1.8 sexual and $1.8 \%$ women experienced physical and sexual violence. Percentage of women who have experienced domestic violence is greater in rural area in comparison to urban area.

\section{Results and Discussions}

TABLE 10 shows the results drawn from ordered Logistic Regression Analysis, using the various parameters.

\subsection{Residence}

For a one unit increase in residence (going from 0 to 1 ) we expect a 1.018 increase in the log odds of being higher level of delivery at health facility. We expect .541 increase in the antenatal care, .414 increase in the gender role attitudes, 1.018 increase in non anemic, .691 increase in knowledge of family planning, .559 increase in knowledge in STD, .146 increase in prenatal care and .309 increase in decision making given all of the other variables in the model are held constant. Results showed that urbanization has positive effects on status of women.

\subsection{Female's Media exposure}

For a one unit increase in media awareness (going from 0 to 1) we expect a .324 increase in the log odds of being higher level of delivery at health facility. We expect .514 increase in the antenatal care, .075 increase in the gender role attitudes, .324 increase in non anemic, 1.063 increase in knowledge of family planning .786 increase in knowledge in STD, .004 increase in prenatal care and .211 increase in decision making, given all of the other variables in the model are held constant. Therefore we can say that women who are aware for media have better status than who are not.

\subsection{Female's Education}

For a one unit increase in female's education (going from 0 to 1 ) we expect a 1.045 increase in the log odds of being higher level of delivery at health facility. We expect 1.696 increase in the antenatal care, .855 increase in the gender role attitudes, 2.208 increase in non anemic, .558 increase in knowledge of family planning ,3.327 increase in knowledge of STD, 1.278 increase in prenatal care and .313 increase in decision making given all of the other variables in the model are held constant. Results show that higher education of women has very positive effect on status of women in every aspect.

\subsection{Partner's Education}

For a one unit increase in partner's education (going from 0 to 1 ) we expect a .655 increase in the log odds of being higher level of delivery at health facility. We expect .757 increase in the antenatal care, .422 increase in the gender role attitudes, .655 increase in non anemic, .526 increase in knowledge of family planning and .662 increase in knowledge in STD, .237 increase in prenatal care and -.007 increase in decision making given all of the other variables in the model are held constant. Therefore, we can say that Partner's education has a positive effect on status of women but it doesn't show positive effect on availing prenatal care for women.

\subsection{Employment}

For a one unit increase in employment (going from 0 to 1) we expect a .063 increase in the log odds of being higher level of delivery at health facility. We expect .576 increase in the antenatal care, .001 increase in the gender role attitudes, .063 increase in non anemic, .067 increase in knowledge of family planning and .404 increase in knowledge in STD, .447 increase in prenatal care and .812 increase in decision making given all of the other variables in the model are held constant. Results show that women's employment in services has positive effect on their status in society.

\subsection{Partner's Employment}

For a one unit increase in Partner's Employment (going from 0 to 1) we expect a .000 increase in the $\log$ odds of being higher level of delivery at health facility. We expect .002 increase in the antenatal care, .012 increase in the gender role attitudes, .005 increase in non anemic, .006 increase in knowledge of family planning ,.003 increase in knowledge in STD, .010 increase in prenatal care and -.001 decrease in decision making given all of the other variables in the model are held constant. Partner's Employment shows positive effects on every aspect of women's status except women's decision making power which is quite surprising. 


\subsection{Religion}

For a one unit increase in religion (going from 0 to 1 ) we expect a .231 increase in the log odds of being higher level of delivery at health facility. We expect .323 increase in the antenatal care, .151 increase in the gender role attitudes, .231 increase in non anemic, .242 increase in knowledge of family planning, .-.081 decrease in knowledge in STD, -.135 decrease in prenatal care and -.087 decrease in decision making given all of the other variables in the model are held constant. Results show that Hindu women are more anemic than others, they are less frequent in availing prenatal care, making decisions and they have less knowledge of STD.

\subsection{Economic Status}

For a one unit increase in economic (going from 0 to 1 ) we expect a .244 increase in the log odds of being higher level of delivery at health facility. We expect .130 increase in the antenatal care, .207 increase in the gender role attitudes, .244 increase in non anemic, .033 increase in knowledge of family planning, .835 increase in knowledge in STD, .034 increase in prenatal care and .530 increase in decision making given all of the other variables in the model are held constant. Higher economic status show positive effect on every aspect on women's status.

\subsection{Castes/Tribes}

For a one unit increase in castes /tribes (going from 0 to 1 ) we expect a -.477 decrease in the log odds of being higher level of delivery at health facility. We expect -.286 decrease in the antenatal care, -.224 decrease in the gender role attitudes, -.477 decrease in non anemic, -.350 decrease in knowledge of family planning, -.067 decrease in knowledge in STD, .142 increase in prenatal care and .238 increase in decision making given all of the other variables in the model are held constant. Women in SC/ST caste are less likely avail health facilities and decision making.

Table 10

Results in Relation to Women's Health Status in India

\begin{tabular}{|c|c|c|c|c|c|c|}
\hline & $\begin{array}{c}\text { Delivery at } \\
\text { Health }\end{array}$ & $\begin{array}{c}\text { Antenatal } \\
\text { Care }\end{array}$ & $\begin{array}{c}\text { Level of } \\
\text { Anemia }\end{array}$ & $\begin{array}{c}\text { Family } \\
\text { Planning }\end{array}$ & $\begin{array}{c}\text { Knowledge } \\
\text { of STD }\end{array}$ & $\begin{array}{c}\text { Prenatal } \\
\text { Care }\end{array}$ \\
\hline Independent variable & Coefficient & Coefficient & Coefficient & Coefficient & Coefficient & Coefficient \\
\hline $\begin{array}{c}\text { Residence } \\
\text { Urban }\end{array}$ & $1.018^{* * * *}$ & $.541^{* * *}$ & $1.018^{* * *}$ & $.691^{* * *}$ & $.559^{* * * *}$ & $.146^{* * * *}$ \\
\hline $\begin{array}{c}\text { Media } \\
\text { Awareness }\end{array}$ & $.324^{* * *}$ & $.514^{* * *}$ & $.324^{* * *}$ & $1.063^{* * *}$ & $.786^{* * *}$ & .004 \\
\hline $\begin{array}{c}\text { Female's Education } \\
\text { Higher Education }\end{array}$ & $1.045^{* * *}$ & $1.696^{* * *}$ & $2.208^{* * *}$ & $.558^{* * *}$ & $3.327^{* * * *}$ & $1.278^{* * *}$ \\
\hline $\begin{array}{c}\text { Partner's Education } \\
\text { Higher Education }\end{array}$ & $.655^{* * *}$ & $.757^{* * *}$ & $.655^{* * *}$ & $.526^{* * *}$ & $.662^{* * * *}$ & $.237^{* * * *}$ \\
\hline $\begin{array}{c}\text { Female's } \\
\text { Employment }\end{array}$ & .063 & $.576^{* * *}$ & .063 & $0.067^{* * *}$ & $.404^{* * * *}$ & $.447^{* * * *}$ \\
\hline $\begin{array}{c}\text { Partner's } \\
\text { Employment }\end{array}$ & .001 & .002 & 0.005 & $.006^{* * *}$ & .003 & $0.010^{* *}$ \\
\hline $\begin{array}{c}\text { Religion of } \\
\text { Household Head } \\
\text { Hindu }\end{array}$ & $.231^{* * *}$ & $.323^{* * *}$ & $.231^{* * *}$ & $.242^{* * *}$ & $-.081^{* * * *}$ & $-.135^{* * * *}$ \\
\hline $\begin{array}{c}\text { Female's Economic } \\
\text { Status } \\
\text { Rich }\end{array}$ & $.244^{* * *}$ & $.130^{* * *}$ & $.244^{* * *}$ & .033 & $.835^{* * * *}$ & .034 \\
\hline $\begin{array}{c}\text { Caste/Tribe } \\
\text { SC-ST }\end{array}$ & $-.477^{* * * *}$ & $-.286^{* * * *}$ & $-.477^{* * *}$ & $-.350^{* * *}$ & $-.067^{* * *}$ & $.142^{* * *}$ \\
\hline
\end{tabular}

$* * *$ denotes $1 \%$, ** denotes $5 \%$ level of significance

\section{Findings \&Suggestions}

Education, occupation, economic status, media awareness and urbanization have positive effect on almost every aspect of women's status. Status of women in urban areas is better than women in rural areas as they are availing all health care facilities and taking part in decision making but a large percentage of women are living in rural areas who are not availing any health care facilities and they don't have any rights in decision making process. A large percentage of women are still neither educated, nor employed and have no media exposure. Study shows that until and these problems will not be addressed, the condition of women's health status will not improve.

Therefore, policies are needed to encourage the rural families to give their girls a chance of attaining higher education and professional courses so that they can get better job opportunities and can economically support their family as 
sons are expected to do. This way they will not only attain self sufficiency but will also help in becoming economically viable for their families which would help in eradicating the curse of being 'economic burden.'

They should also be encouraged to start their own business and loan should be provided for their entrepreneurship at very low interest and the process of availing loan facilities should be made easy. All these measures would help in removing the attitude of Indians that 'investing in girls is unnecessary'.

Study revealed that health and empowerment status of women is much better in urban areas, compared to their counterparts in rural India. Urban women are highly educated, employed in high profile services, are consciously aware of media and are included in the higher economic groups. But the percentage of women in these groups are very small, a large percentage of women residing in rural India are still far behind. They are not even availing the basic necessities so for large percentage of women availing health facilities has become a luxury. Their lack of knowledge of family planning measures and sexually transmitted diseases has caused a major cause of concern as more and more women are getting infected to deadly diseases. Therefore, it is necessary to make health facilities cheaper and easily access able to women.

\section{Conclusion}

Girls in India are discriminated against in other ways as well - fewer months of breastfeeding, less nurturing and play, less medical treatment if they fall ill, less special food, less prenatal attention. As a result, girls are far more susceptible than boys to disease and infections, leading to poor health and a shorter lifespan. It is this lifelong discrimination in nurturing and care that is the real killer of girls, less visible and less dramatic, but as unequivocally lethal as female foeticide and infanticide (UNICEF, 1998).

As UN Secretary Kofi Anan had stated, "Gender equality is more than a goal in itself. It is a precondition for meeting the challenge of reducing poverty, promoting sustainable development and building good governance."

This recognition is currently missing in India. Transforming the prevailing social discrimination against women must become the top priority. This must happen at war footing before it gets very late to improve the social and economic status of women.

In this way, a synergy of progress can be achieved. As women receive more education and training, they will earn more money. As women earn more money - as has been repeatedly shown - they spend it in the further education and health of their children, as opposed to men, who often spend it on drink, tobacco or other women.

As women rise in economic status, they will gain greater social standing in the household and the village, and will have greater voice. As women gain influence and consciousness, they will make stronger claims to their entitlements gaining further training, better access to credit and higher incomes - and command attention of police and courts when attacked.

As son preference declines and acceptance of violence declines, families will be more likely to educate their daughters, and age of marriage will rise. As women are better nourished and marry later, they will be healthier, more productive, and will give birth to healthier babies.

Only through action to remedy, discrimination against women can be eradicated, which was the vision of India's Independence - an India where all people have the equal chance to live, attain healthy and productive lives - be realized.

No policies or campaign would be successful without public support, awareness and proper implication. There is a need to raise the voice against gender discrimination in health care facilities and to improve the status of women at the every possible level and should it not be stopped until and unless this problem is totally removed from the society.

\section{References}

[1] A. Sen, Many Faces of Gender Inequality, Frontline, 18 (22), Oct. 27 - Nov. 09, 2001.

[2] Census of India 2011, Office of the Registrar General \& Census Commissioner, India.

[3] Shelah S. Bloom, David Wypij, Monica Das. Gupta, Dimensions of Women's Autonomy and the Influence on Maternal Health Care Utilization in a North Indian City, Demography, 38( 1), Population Association of America, 2001.

[4] Bhat, P. N. Mari and. A. J. Francis Zavier, Fertility Decline and Gender Bias in Northern India, Demography, 40(4), Population Association of America Northern India,2003,637-657.

[5] Rohini P. Pandey, Selective Gender Differences in Childhood Nutrition and Immunization in Rural India: The Role of Siblings, Demography, 40(3), Population Association of America, 2003.

[6] Bhat, P. N Mari, K Navaneetham, and S. Irudaya Rajan, Maternal Mortality in India: Estimates from a Regression Model, Studies in Family Planning, 26(4), Population Council India, 1995.

[7] K. S. Sugathan, Vinod Mishra, and Robert D Retherford, Promoting Institutional Deliveries in Rural India: The Role of AntenatalCare Services, National Family Health Survey Subject Reports, 20, International Institute for Population Sciences, Mumbai. 2001.

[8] K. B. Pathak, Griffith Feeney, \& Norman Luther, Alternative Contraceptive Methods and Fertility Decline in India, National Family Health Survey Subject Reports, 7, International Institute for Population Sciences, Mumbai,1998.

[9] SRS Bulletin, 45(1), Sample Registration System, Office of the Registrar General; India, 2011.

[10] Ansley J. Coale, Excess Female Mortality and the Balance of the Sexes in the Population: An Estimate of the Number of "Missing Females", Population and Development Review, 17(3), Population Council, 1991. 